DOI: http://dx.doi.org/10.18203/2320-1770.ijrcog20173474

Original Research Article

\title{
Genital tuberculosis and infertility
}

\section{Prajakta Shende*, Shalini Mahana Valecha, Manisha Gandhewar, Diwija Dhingra}

Department of Obstetrics and Gynecology, ESI, PGIMSR and Model Hospital, Mumbai, Maharashtra, India

Received: 01 June 2017

Accepted: 27 June 2017

\section{*Correspondence:}

Dr. Prajakta Shende,

E-mail: praj.shende@gmail.com

Copyright: (c) the author(s), publisher and licensee Medip Academy. This is an open-access article distributed under the terms of the Creative Commons Attribution Non-Commercial License, which permits unrestricted non-commercial use, distribution, and reproduction in any medium, provided the original work is properly cited.

\section{ABSTRACT}

Background: An analytical study to diagnose genital tuberculosis, using various modalities, it's treatment options and fertility outcomes in infertile labour class women.

Methods: A prospective study, where 120 women, presented to hospital due to infertility were subjected to hysterolaparoscopy over 36 months. Endometrium sent for TB-PCR and HPR. Those diagnosed with GTB were given AntiTubercular Drugs as per standard regimes and their fertility outcome was studied.

Results: Out of 120 women, 32(27\%) were diagnosed with GTB using accepted clinical criteria, TB-PCR and endometrial HPR. 30 of these 32 were diagnosed by HLscopic picture (94\%) alone, 18 by positive endometrial TBPCR $(58 \%)$ and another 3 by HPR (10\%). Among 32 women treated, $9(28 \%)$ conceived after treatment.

Conclusions: High incidence of GTB amongst the labour class warrants strong suspicion and early diagnosis using hystero-laparoscopy and prompt treatment to minimize the short and long-term effects of GTB on fertility.

Keywords: Anti-tubercular drugs, Fertility, GTB, HLscopy, TB-PCR

\section{INTRODUCTION}

In 2014, there were an estimated 9.6 million new cases of $\mathrm{TB}$, of which 3.2 million were among women. ${ }^{1}$ Reportedly about 9 per cent of all extra- pulmonary tuberculosis cases are genital tract $\mathrm{TB} .^{2}$

Genital tuberculosis is a disease of silent nature. Infertility is the most common presentation amongst women in the childbearing age group (43-74\%). Other clinical presentations include oligomenorrhoea (54\%), amenorrhea (14\%), menorrhagia (19\%), abdominal pain $(42.5 \%)$, dyspareunia (5-12\%) and dysmenorrhea (12$30 \%)^{2}$ The worldwide incidence of GTB is approximately $5-10 \%$ in infertile women. It varies from as low as $0.69 \%$ in some developed countries to as high as $19 \%$ in India. ${ }^{3}$ Diagnosing genital tuberculosis is a challenge because of varied clinical presentations, diverse results on imaging and laparoscopy, and a mixed bag of bacteriological and serological tests. ${ }^{4}$ Diagnosis by culture of the tubercle bacillus from tissue sampled from the genital tract is the yardstick for diagnosis and remains the gold standard. However, in spite of inoculation into multiple media only $5-6 \%$ of samples yield microbiological proof of mycobacteria by culture, the reason being the paucibacillary nature of the organism, bacteriologically mute genital lesions, presence of bacteriostatic substance in endometrium and cyclic shedding of endometrium which leads to inadequate granuloma formation in each cycle. ${ }^{5}$

The Fallopian tubes are the most common and initial site of involvement (90-100\%), followed by endometrium in $50-60 \%$ of cases. $^{6}$ The tuberculin test has a poor sensitivity and specificity in laparoscopically diagnosed GTB. DNA- Polymerase Chain Reaction (PCR) is now affordable and a much more reliable test for rapid and improved diagnosis. Infertile women without tubal or 
endometrial damage given early anti-tuberculosis treatment, based on a positive endometrial TB-PCR test, have an excellent chance of early spontaneous conception. $^{7}$

\section{METHODS}

A prospective study was carried out between January 2012 and January 2015 on 120 women presenting with infertility. Ethics committee permission was duly sought from the Institute for study design. This study was conducted in an organization, which provides social and health security to labour class population. Detailed history was taken, clinical examination, hematological investigations, pelvic ultrasound, semen analysis, hormonal assays were done. Hysterosalpingogram (HSG) was not done in our study, but the images of women who already had such an investigation were reviewed for tubercular findings. A past history of tuberculosis as well as Anti tubercular drug use was noted in detail, along with any history of tubercular contact. All women of primary or secondary infertility were included. Patients with male factor infertility and anovulation were excluded from the study. GTB associated with co-morbid conditions like medical disorders, HIV, cancers were not noted in our study group. 120 women who attended out patient department for infertility were selected for the study after their written and informed consent.

Women of reproductive age group (20-40years) presenting with primary or secondary infertility of more than one year duration and an active married life were included in the study. All 120 women were posted for diagnostic hystero-laparoscopy after informed consent. Endometrial curettage was done during the procedure and the sample was sent for histopathology and the specialized laboratory for TB-PCR. Laparoscopic findings like tubal blocks, peritubal adhesions, hydrosalpinges, tubo-ovarian masses and tubercles were noted. Hysteroscopic findings like cervical stenosis, narrow uterine cavity, endometrial bands and synechia, blocked tubal ostia, scanty endometrium and tubercles in the endometrium were documented. In our study, we sent endometrial TB-PCR of all women, irrespective of hystero- laparoscopic findings.

Gross appearance of healthy endometrial cavity on hysteroscopy and normal pelvic findings on laparoscopy were the criteria used to exclude GTB. These findings again correlated with clinical history, detailed examination and additional endometrial TB-PCR. Thus, we used multiple diagnostic tools to establish or rule-out the existence of GTB. In one woman of abdominal tuberculosis, introduction of trocar and cannula was difficult from supra and infra umbilical site, hence trocar and cannula was introduced through Palmer`s point. In another woman, we were unable to negotiate the cervical os, due to cervical stenosis. Hence hysteroscopy was abandoned. This patient showed extensive signs of tuberculosis on laparoscopy.

\section{RESULTS}

In present study, a total of 120 women had undergone diagnostic hystero-laparoscopy, for infertility. The mean duration of infertility was 3.7 years ranging from 2 to 10 years. All women were between 22 years to 39 years of age.

Table 1: Mode of diagnosis of genital tuberculosis $(\mathrm{N}=32)$.

\begin{tabular}{|l|l|}
\hline Mode of diagnosis & $\begin{array}{l}\text { No of patients } \\
\text { diagnosed with GTB }\end{array}$ \\
\hline Hystero-laparoscopy & $30 / 32(94 \%)$ \\
\hline TB-PCR & $18 / 31(58 \%)$ \\
\hline HPR & $3 / 31(10 \%)$ \\
\hline
\end{tabular}

$32(27 \%)$ women were diagnosed as genital tuberculosis by combination of hystero laparoscopic findings, histopathological and endometrial DNA-PCR technique confirmation. Of these 32 women, $13(40.62 \%)$ had secondary infertility and remaining 19 (59.38\%) had primary infertility. $5(15.62 \%)$ were previously diagnosed with pulmonary or extra pulmonary tuberculosis and had completed a full course of Anti-tubercular treatment as per WHO CAT 1 regime. Only 4 (12.5\%) women had admitted to a history of tubercular contact.

Table 2: Laparoscopic findings $(\mathrm{N}=120)$.

\begin{tabular}{|l|l|}
\hline Pindings & Number \\
\hline PCOS (Polycystic ovarian syndrome) & $28(23 \%)$ \\
\hline Peritubal adhesions & $21(18 \%)$ \\
\hline Tubal block & $12(10 \%)$ \\
\hline Beaded tube & $8(7 \%)$ \\
\hline Cornual block & $11(9 \%)$ \\
\hline Normal & $35(29 \%)$ \\
\hline Hydrosalpinx & $10(8 \%)$ \\
\hline Clubbed fimbria & $10(8 \%)$ \\
\hline Frozen pelvis & $8(7 \%)$ \\
\hline Endometriosis & $23(19 \%)$ \\
\hline Others (fibroid, anomalous uterus) & $12(10 \%)$ \\
\hline
\end{tabular}

Table 3: Findings on hysteroscopy $(\mathrm{N}=120)$.

\begin{tabular}{|ll|}
\hline Finding & No \\
\hline Normal & $66(55 \%)$ \\
\hline Synechia/fibrosed endometrium & $22(18 \%)$ \\
\hline Other (fibroid, polyp, anomaly) & $14(12 \%)$ \\
\hline Narrow cavity & $10(8 \%)$ \\
\hline Scarring of cornu & $5(4 \%)$ \\
\hline Cervical stenosis & $1(1 \%)$ \\
\hline
\end{tabular}

Of these, a 94\% (30/32) had clearly seen findings pointing towards TB on hystero- laparoscopy, such as beaded tubes, peritubal adhesions, frozen pelvis, blocked tubes, tubercles on the pelvic organs. Hysteroscopic findings mainly suggestive of tuberculosis include 
fibrosed endometrium, narrow cavity and cornual scarring. However, only in $18(58 \%)$ patients TB-PCR was positive. Out of 32 women, in $2(6 \%)$ women, we did not get any significant finding on hystero- laparoscopy. In $3(10 \%)$ of the diagnosed women, endometrial histopathology revealed presence of granulomatous lesions.

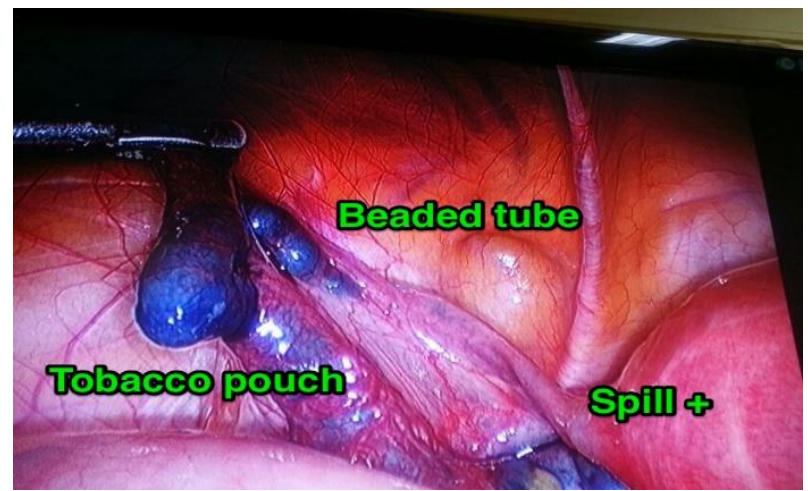

Figure 1: Laparoscopic finding suggestive of GTB: beaded tube, tobacco pouch (*although spill is present, tubes are clearly damaged).

These figures show beaded tubes, tobacco pouch appearance of tubes after dye test and congested inflamed hydrosalpinx.

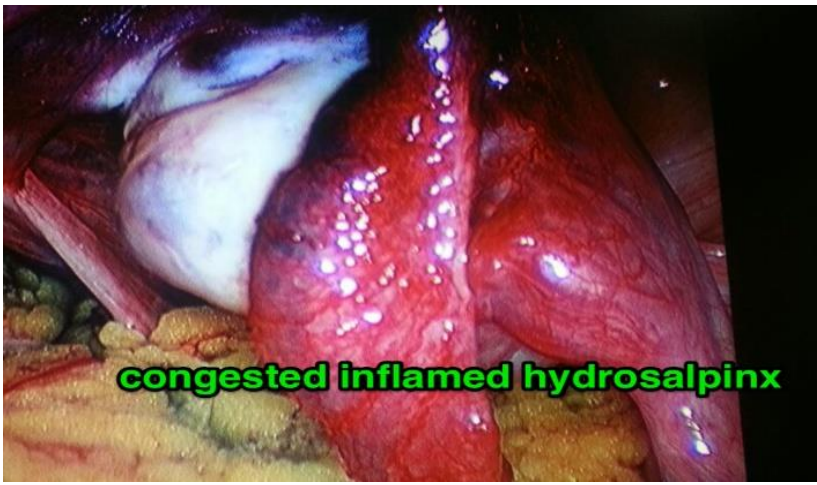

Figure 2: Congested inflamed hydrosalpinx.
32 women after diagnosis were given standard 4 drugs anti-tubercular treatment (ATT) for 6 months. In 10 women, we added steroids, for the initial 2 months, to decrease the occurrence of fibrosis. One woman was diagnosed with lumbosacral Koch`s hence anti tubercular drugs were given for 9 months.

8 women had a frozen pelvis. Though they were given option of assisted reproduction, they chose adoption due to economic reasons. For other women, we advised Controlled Ovarian Hyper stimulation with IUI after completion of ATT.

Out of the, 32 diagnosed women of genital tuberculosis, 9 women conceived with treatment $(28 \%)$. Of these, 3 conceived spontaneously, within 2 months of treatment. Rest 6 conceived on Clomiphene +IUI (Intra-Uterine Insemination).

Table 4: Outcome of study $(\mathrm{N}=9)$.

\begin{tabular}{|l|l|}
\hline Outcome & $\begin{array}{l}\text { No of women/ } \\
\text { total with GTB }\end{array}$ \\
\hline Delivered & $5 / 32(16 \%)$ \\
\hline Spontaneous abortion & $2 / 32(6 \%)$ \\
\hline Ectopic & $1 / 32(3 \%)$ \\
\hline Biochemical pregnancy & $1 / 32(3 \%)$ \\
\hline
\end{tabular}

Mode of delivery for these women: 2 underwent cesarean section for obstetric causes, while 3 delivered vaginally. One woman, delivered vaginally, had retained placenta, which was managed conservatively in the initial period. Later on, she underwent obstetric hysterectomy for placental site sepsis.

\section{DISCUSSION}

Classically, GTB has been described inevitably as a disease of reproductive age women. The presenting symptoms are related to menstrual irregularities and infertility. Early diagnosis and treatment will improve fertility outcome.

Table 5: Genital tuberculosis.

\begin{tabular}{|c|c|c|c|c|c|c|}
\hline Studies & Present study & Puri et $\mathbf{a l}^{8}$ & Kulshrestha et al ${ }^{9}$ & Baxi et al ${ }^{10}$ & Sharma et al ${ }^{11}$ & Bapna et al ${ }^{12}$ \\
\hline GTB & $27 \%$ & & $60.2 \%$ & & & $16.4 \%$ \\
\hline TB PCR & $58 \%$ & $46.67 \%$ & $41.3 \%$ & $32 \%$ & $64.7 \%$ & \\
\hline HL scopy & $93 \%$ & & $9.1 \%+37.4 \%$ & $42.52 \%$ & $47 \%$ & \\
\hline Conception rate & $28 \%$ & $19.35 \%$ & $22.9 \%$ & & & $19.1 \%$ \\
\hline
\end{tabular}

Culture of Mycobacterium is the gold standard but has a limited yield. In the present study, $58 \%$ positive TB-PCR results were comparable with a study in New Delhi, which documented $56 \%$ of infertile patients as TB-PCR positive. ${ }^{5}$ Study by Puri et al gives $46.67 \%$ positive TB PCR results. ${ }^{8}$ In a study by Kulshrestha et al genital tuberculosis was diagnosed in $60.2 \%$ infertility women. ${ }^{9}$ Laparoscopy indicated definitive GTB in $9.1 \%$ and 
probable GTB in $37.4 \%$, and TB-PCR was positive in $41.3 \%$ of women. Diagnosing GTB by presence of granulomatous lesions on HPR is difficult due to cyclic shedding of endometrium. A study by Bapna et al, documented $12.5 \%$ women of GTB having positive histopathological reports. ${ }^{12}$ In the present study, we diagnosed $10 \%$ of GTB cases on endometrial HPR.

In this study, conception rate is $28 \%$ after starting AKT. Where regular and complete treatment was taken there is an increase in conception rate. However, in prolonged infertility cases the take home baby rate is much less.

\section{CONCLUSION}

TB being endemic in developing countries like India, it is often a leading cause of infertility. GTB being secondary to other sites like lungs and lymph nodes is often insidious and asymptomatic. By the time patients report with infertility, already the damage has started. Further delay in diagnosis is likely to compound the damage already caused by TB, making infertility more profound and irreversible. Pathognomonic appearances on hysterolaparoscopy strongly point in the direction of GTB. Hystero-laparoscopy also diagnoses concomitant causes of infertility like, endometriosis, PCOS and uterine anomalies. TB-PCR is a reliable diagnostic tool. ATT started early, may give a significant advantage in improving the chances of conception. Therefore, in countries where TB is endemic, early and aggressive strategies should be pursued to diagnose and treat TB. A multi-pronged approach to diagnosis increases the chances of successfully diagnosing this destructive disease.

Funding: No funding sources

Conflict of interest: None declared

Ethical approval: The study was approved by the Institutional Ethics Committee

\section{REFERENCES}

1. WHO Global TB Control Report. 20 $0^{\text {th }}$ edition. 2015. Available at http://www.who.int/tb/publications/global_report/gtb r15_main_text.pdf
2. Bose M. Female genital tract tuberculosis: How long will it elude diagnosis? Indian J Med Res. 2011;134(1):13-14.

3. Abdelrub AS, Al Harazi AH. Al Harazi. Genital tuberculosis is common among females with tubal factor infertility: observational study. Alexandria J Med. 2015;51:321-4.

4. Jassawalla MJ. Genital tuberculosis: a diagnostic dilemma. J Obstet Gynecol India. 2006;56:203-4.

5. Bhanu NV, Singh UB, Chakraborty M, Suresh N, Arora J, Rana T, et al. Improved diagnostic value of PCR in the diagnosis if female genital tuberculosis leading to infertility. J Med Microbiol. 2005;54:92731.

6. Thangappah RBP, Paramasivan CN, Narayanan S. Evaluating PCR, culture and histopathology in the diagnosis of female genital tuberculosis. Indian $\mathbf{J}$ Med Res. 2011;134:40-6.

7. Jindal UN, Verma S, Bala Y. Favorable infertility outcomes following anti-tubercular treatment prescribed on the sole basis of a positive polymerase chain reaction test for endometrial tuberculosis. Human Reprod. 2012;27(5):1368.

8. Suman P, Bhavana B. Diagnostic value of PCR in female genital TB and its therapeutic implications. J Obstet Gynecol India. 2009;59(1):67-70.

9. Kulshrestha V, Kriplani A, Agarwal N, Singh UB, Rana T. Genital tuberculosis among infertile women and fertility outcome after antitubercular therapy. Int J Gynecol Obstet. 2011;113(3):229-34.

10. Baxi A, Neema H, Kaushal M, Sahu P, Baxi D. Genital tuberculosis in infertile women: Assessment of endometrial TB PCR results with laparoscopic and hysteroscopic features. J Obstet Gynecol India. 2011;61(3):301-6.

11. Sharma JB, Roy KK, Pushparaj M, Kumar S, Malhotra N, Mittal S. Laparoscopic findings in female genital tuberculosis. Arch Gynecol Obstet. 2008;278(4):359-64.

12. Neelam B, Mohanlal S, Namita K. Genital tuberculosis and its consequences on subsequent fertility. J Obstet Gynecol India. 2005;55(6):534-7.

Cite this article as: Shende P, Valecha SM, Gandhewar M, Dhingra D. Genital tuberculosis and infertility. Int J Reprod Contracept Obstet Gynecol 2017;6:3514-7. 